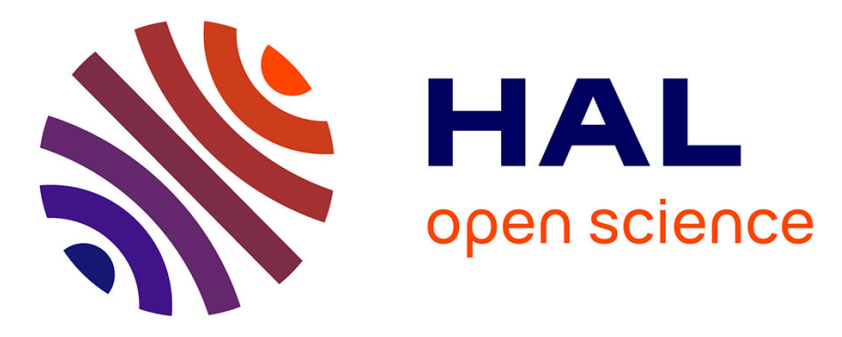

\title{
In situ continuous monitoring of nitrogen with ion-selective electrodes in a constructed wetland receiving treated wastewater: An operating protocol to obtain reliable data
}

S. Papias, M. Masson, S. Pelletant, Stéphanie Prost-Boucle, Catherine Boutin

\section{- To cite this version:}

S. Papias, M. Masson, S. Pelletant, Stéphanie Prost-Boucle, Catherine Boutin. In situ continuous monitoring of nitrogen with ion-selective electrodes in a constructed wetland receiving treated wastewater: An operating protocol to obtain reliable data. Water Science and Technology, 2018, 77 (6), pp.1706-1713. 10.2166/wst.2018.052 . hal-01884674

\author{
HAL Id: hal-01884674 \\ https://hal.science/hal-01884674
}

Submitted on 1 Oct 2018

HAL is a multi-disciplinary open access archive for the deposit and dissemination of scientific research documents, whether they are published or not. The documents may come from teaching and research institutions in France or abroad, or from public or private research centers.
L'archive ouverte pluridisciplinaire HAL, est destinée au dépôt et à la diffusion de documents scientifiques de niveau recherche, publiés ou non, émanant des établissements d'enseignement et de recherche français ou étrangers, des laboratoires publics ou privés. 


\section{In situ continuous monitoring of nitrogen with ion-selective electrodes in a constructed wetland receiving treated wastewater: an operating protocol to obtain reliable data}

5 Sandrine Papias, Matthieu Masson*, Sébastien Pelletant, Stéphanie Prost-Boucle and Catherine Boutin

Irstea, UR MALY Milieux aquatiques, écologie et pollutions, centre de Lyon-Villeurbanne, 5 rue de la Doua, BP 32108, 69616 Villeurbanne Cedex, France.

10

*corresponding author: matthieu.masson@irstea.fr

\section{Abstract}

Constructed Wetlands receiving treated wastewater (CWtw) are placed between Wastewater Treatment Plants and receiving water bodies, under the perception that they increase water quality. A better understanding of the CWtw functioning is required to evaluate their real performance. To achieve this, in situ continuous monitoring of nitrate and ammonium concentrations with lonSelective Electrodes (ISEs) can provide valuable information. However, this measurement needs precautions to produce good data quality, especially in areas with high effluent quality requirements. In order to study the functioning of a CWtw instrumented with 6 ISEs probes, we have developed an appropriate methodology for probe management and data processing. It is based on an evaluation of performance in the laboratory and an adapted field protocol for calibration, data treatment and validation. The result is an operating protocol concerning an acceptable cleaning frequency of two weeks, a complementary calibration using CWtw water, a drift evaluation and the determination of limits of quantification ( $1 \mathrm{mgN} / \mathrm{L}$ for ammonium and $0.5 \mathrm{mgN} / \mathrm{L}$ for nitrate). An example of a 9-month validated dataset confirms that it is fundamental to include the technical limitations of the measuring equipment and set appropriate maintenance and calibration methodologies in order to ensure an accurate interpretation of data.

Keywords: ammonium, electrochemical sensor, free-water surface constructed wetland, long-term monitoring, nitrate 


\section{INTRODUCTION}

The quality of surface waters with respect to eutrophication and nutrients concentrations is an objective of the Water Framework Directive which asks to achieve a good chemical and ecological status of all water bodies across the European Union by 2021. Moreover, the classification of a territory as a nutrient-sensitive area often implies more binding emission limit values for nitrogen and phosphorus for the Wastewater Treatment Plants (WWTPs). In this context, the use of Constructed Wetlands receiving treated wastewater (CWtw) has recently become attractive in France under the perception that they increase water quality. Placed between the WWTP and the receiving water body, the CWtw is not included in the WWTP. Therefore, more than $500 \mathrm{CWtws}$ are in operation in France, most of them have been built in the last 5 years (Prost-Boucle \& Boutin 2013). It also highlights that they have a multitude of configurations (meadows, ponds, ditches and "miscellaneous", i.e. specific design using filling material) and intended outcomes, but no clear link between them. In these systems, the fate of conventional pollutants, such as nitrogen, depends on processes occurring in the different compartments of CWtws: free water, soil, plants. In order to monitor nitrogen concentrations along the CWtw and to assess CW performances, in situ and continuous measurement can be considered as a method of choice compared to classic method needing field sampling then laboratory measurement (Olsson et al. 2014). Ion-Selective Electrodes (ISEs), electrochemical sensors based on potentiometric methods (Cammann 1979), are more and more installed in WWTPs as they allow in situ and continuous measurement of ions such as nitrate and ammonium (Åmand et al., 2013). However, ISEs need carefully precautions and specific protocols must be deployed (installation, calibration, maintenance, data validation) to guarantee reliable data (Guigues et al., 2002; Thomann et al. 2002). In the case of sensitive areas with low outlet water concentrations for nitrogen (typically $<2 \mathrm{mgN} / \mathrm{L}$ for ammonium), management of ISE probes and data processing must be considered as a challenge because the limits of the sensors may be met (Kaelin et al. 2008).

In this context, we propose a reliable methodology to increase the quality of data from ISE probes installed in a CWtw characterized by low ranges of nitrate $\left(\mathrm{NO}_{3}-\mathrm{N}\right)$ and ammonium $\left(\mathrm{NH}_{4}-\mathrm{N}\right)$ concentrations. This methodology is based on an evaluation of probe performance in the laboratory and an adapted field protocol for calibration, data treatment and validation. An example of treated and validated data shows the potential and limits of these probes for the long-term monitoring (9 months) of the nitrogen dynamic in the CWtw. 


\section{METHODS}

\section{Site description and instrumentation}

The studied CWtw is located in the city of Marguerittes (Southern France) and is operated since summer 2013. The CWtw is similar to a free water surface CW and consists of two ponds in series, $\mathrm{P} 1$ and $\mathrm{P} 2$ (Figure 1), of $3575 \mathrm{~m}^{2}$ and $6370 \mathrm{~m}^{2}$ respectively. The pond $\mathrm{P} 1$ receives between 1000 and $3000 \mathrm{~m}^{3} / \mathrm{d}$ of treated wastewater from the 15000 population equivalent WWTP. Then, the water flows into the pond P2 composed of five different areas before discharging into the Canabou River. The measured average hydraulic residence time (hydraulic tracing with uranine/fluorescein; recovery rates between 69 and 90\%) along the CWtw is approximately 3 days.

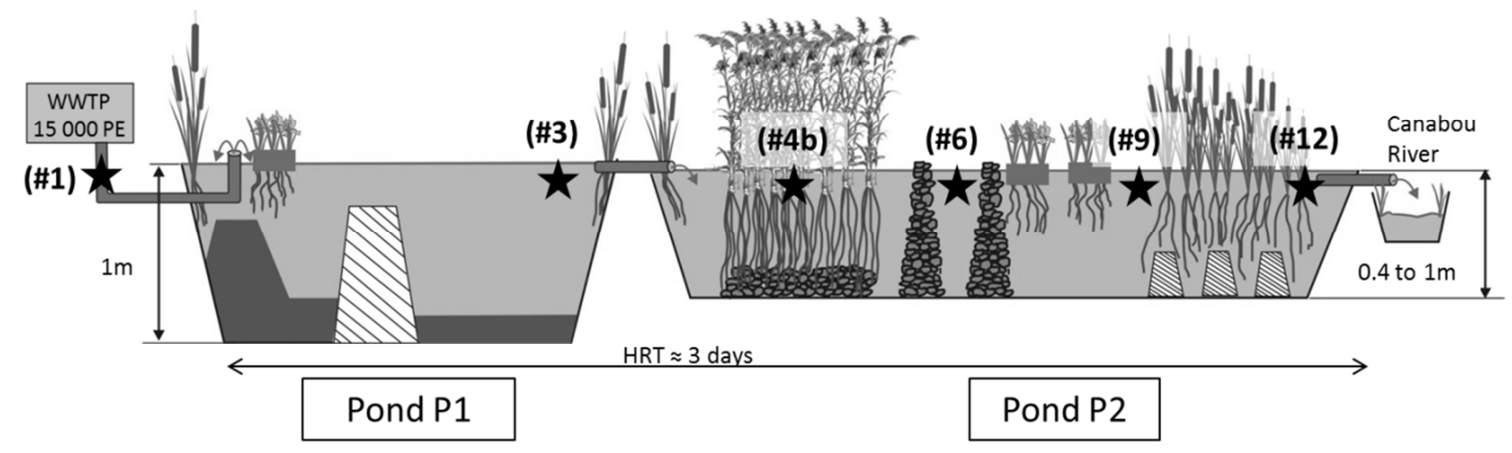

Figure 1 Schematic representation of the CWtw constituted by two main ponds (P1 and P2) and location of the 6 ISE probes (\#1), (\#3), (\#4b), (\#6), (\#9) and (\#12) (black stars).

The CWtw has been instrumented with 6 ISE probes (specific sensors VARION AN/A WTWSecomam) measuring $\mathrm{NO}_{3}-\mathrm{N}$ and $\mathrm{NH}_{4}-\mathrm{N}$ concentrations with a 5-min step recording. This study presents a 9-month dataset running from August 2015 to April 2016. A focus is made on probe \#1, located at the outlet of the WWTP, which represents the influent of the CWtw (Figure 1). According to manufacturer instructions, the measurement ranges of $\mathrm{NO}_{3}-\mathrm{N}$ and $\mathrm{NH}_{4}-\mathrm{N}$ concentrations are 0.1$100 \mathrm{mg} / \mathrm{L}$ with a response time of $3 \mathrm{~min}$ in both surface water and wastewater. During the installation of new sensors (typically every 6-9 months), a calibration with manufacturer solutions (from 5 to $60 \mathrm{mgN} / \mathrm{L}$ ) was systematically performed. It was followed by a matrix adjustment using water from the CWtw spiked with sodium nitrate and ammonium sulfate (AnalaR NORMAPUR quality) to reach $\mathrm{NO}_{3}-\mathrm{N}$ and $\mathrm{NH}_{4}-\mathrm{N}$ concentrations around $5 \mathrm{mgN} / \mathrm{L}$.

\section{Measurement of reference $\mathrm{NO}_{3}-\mathrm{N}$ and $\mathrm{NH}_{4}-\mathrm{N}$ concentrations}

lonic chromatography was used as reference method for the determination of $\mathrm{NO}_{3}-\mathrm{N}$ and $\mathrm{NH}_{4}-\mathrm{N}$ concentrations in the solutions used for laboratory tests and in the grab samples collected in the CWtw. The NF EN ISO 10304-1 (2009) and NF EN ISO 14911 (1999) standards were applied, 
respectively, for $\mathrm{NO}_{3}-\mathrm{N}$ and $\mathrm{NH}_{4}-\mathrm{N}$ measurements. Limits of Quantification (LoQ) for $\mathrm{NO}_{3}-\mathrm{N}$ and $\mathrm{NH}_{4}^{-}$ $\mathrm{N}$ are $0.45 \mathrm{mgN} / \mathrm{L}$ and $0.02 \mathrm{mgN} / \mathrm{L}$ respectively, and precision was better than $6 \%$ for $\mathrm{NO}_{3}-\mathrm{N}$ and $8 \%$ for $\mathrm{NH}_{4}-\mathrm{N}$.

\section{Laboratory tests}

The performance of ISE probes was evaluated in laboratory based on the ISO 15839 (2003) standard (Rieger et al. 2002). The applied protocol needed the preparation of several solutions spiked with well-defined $\mathrm{NO}_{3}-\mathrm{N}$ and $\mathrm{NH}_{4}-\mathrm{N}$ concentrations (ammonium sulfate and sodium nitrate, AnalaR NORMAPUR quality). French bottled mineral water (Saint Antonin) was used for its composition without nitrogen $\left(\mathrm{NO}_{3}-\mathrm{N}\right.$ and $\mathrm{NH}_{4}-\mathrm{N}$ concentrations were below $0.45 \mathrm{mg} / \mathrm{L}$ and $0.02 \mathrm{mg} / \mathrm{L}$, respectively). Because the measurement is influenced by the ionic strength and the matrix of the measuring water (Rieger et al. 2002), the solution used for the experimentations ( $S_{\text {exp }}$ ) was prepared by diluting 3-times the mineral water with ultra-pure water to fit the ionic strength of the $\mathrm{CWtw}$. $\mathrm{NO}_{3}-\mathrm{N}$ and $\mathrm{NH}_{4}-\mathrm{N}$ concentrations of the different solutions prepared by spiking $\mathrm{S}_{\text {exp }}$ were systematically controlled using the reference methods. The following key parameters have been evaluated:

- The response times of the sensors to sudden increasing and decreasing changes of $\mathrm{NO}_{3}-\mathrm{N}$ and $\mathrm{NH}_{4}-\mathrm{N}$ concentrations were estimated by successively immersing the probe in $\mathrm{S}_{\exp }$ spiked with $\mathrm{NO}_{3}-\mathrm{N}$ and $\mathrm{NH}_{4}-\mathrm{N}$ concentrations of 5.0 and $80 \mathrm{mgN} / \mathrm{L}$ (i.e. $5 \%$ and $80 \%$ of the concentration range).

- The linearity between measured concentrations and theoretical concentrations was evaluated by measuring $\mathrm{NO}_{3}-\mathrm{N}$ and $\mathrm{NH}_{4}-\mathrm{N}$ concentrations in $\mathrm{S}_{\text {exp }}$ adjusted to $0.5,1.0,2.0,5.0,10,25$, 40, 60, 80 and $95 \mathrm{mgN} / \mathrm{L}$. This experiment was repeated 6-times in intermediate precision conditions. The check of the linearity was performed by comparing the mean bias for each concentration with maximum permissible deviation values determined on the basis of the laboratory expertise.

- Based on NF T 90-210 (2009) standard, assumed LoQs of 0.5 and $1.0 \mathrm{mgN} / \mathrm{L}$ for $\mathrm{NO}_{3}-\mathrm{N}$, and 1.0 and $2.0 \mathrm{mgN} / \mathrm{L}$ for $\mathrm{NH}_{4}-\mathrm{N}$ have been analyzed.

- The interferences were quantified in a solution containing $\mathrm{NO}_{3}-\mathrm{N}$ and $\mathrm{NH}_{4}-\mathrm{N}$ concentrations of $5.0 \mathrm{mgN} / \mathrm{L}$ in which successive adds of chloride potassium were completed (maximum concentration for chloride : $700 \mathrm{mg} / \mathrm{L}$; for potassium : $800 \mathrm{mg} / \mathrm{L}$ ) as chloride and potassium ions represent the main interferences for $\mathrm{NO}_{3}-\mathrm{N}$ and $\mathrm{NH}_{4}-\mathrm{N}$ measurements, respectively (Winkler et al. 2004). 


\section{Field procedures}

The maintenance frequency has been set at two weeks. Sensors were cleaned with CWtw water then tap water if necessary. If biofouling was observed, a soft tissue could be used. To evaluate the impact of the cleaning frequency on measurements, $\mathrm{NO}_{3}-\mathrm{N}$ and $\mathrm{NH}_{4}-\mathrm{N}$ concentrations measured by the probes before and after cleaning procedure were systematically recorded.

ISE probes are subject to drift over time (Winkler et al. 2004) and a protocol was developed to evaluate this potential drift. After cleaning procedure, the probes were systematically immerged in a drift control solution ( $\mathrm{Sol}_{D C}$ ) for $\mathrm{NO}_{3}-\mathrm{N}$ and $\mathrm{NH}_{4}-\mathrm{N}$ measurement. The Sol ${ }_{D C}$ consists on filtered water $(<0.45 \mu \mathrm{m})$ collected in the CWtw and spiked with ammonium sulfate and sodium nitrate (AnalaR NORMAPUR quality) to reach $\mathrm{NO}_{3}-\mathrm{N}$ and $\mathrm{NH}_{4}-\mathrm{N}$ concentrations of $5 \mathrm{mgN} / \mathrm{L}$. The Sol $\mathrm{DC}_{\mathrm{DC}}$ was stored at $4^{\circ} \mathrm{C}$ in the dark. Every two weeks, the $\mathrm{NO}_{3}-\mathrm{N}$ and $\mathrm{NH}_{4}-\mathrm{N}$ concentrations of the Sol $\mathrm{DC}_{\mathrm{DC}}$ were measured using reference methods to control the stability of $\mathrm{NO}_{3}-\mathrm{N}$ and $\mathrm{NH}_{4}-\mathrm{N}$ concentrations, and then $1 \mathrm{~L}$ of Sol $\mathrm{DC}_{\mathrm{C}}$ was brought to the field for drift control.

Despite the initial manufacturer calibration and matrix adjustment, additional local calibration has been performed. Every two weeks, water was systematically sampled close to each probe just before the cleaning maintenance. The $\mathrm{NO}_{3}-\mathrm{N}$ and $\mathrm{NH}_{4}-\mathrm{N}$ concentrations given by the probes during the sampling were associated with the corresponding concentrations measured in the grab samples by reference methods in laboratory. The resulting dataset was split in two parts: $50 \%$ were used for local calibration and the other $50 \%$ were used for data validation. In order to cover a broader range of concentrations, 3 additional couples of points were produced by using water from the CWtw adjusted to 10,15 and $20 \mathrm{mgN} / \mathrm{L}$ for $\mathrm{NO}_{3}-\mathrm{N}$ and 5.0, 10 and $15 \mathrm{mgN} / \mathrm{L}$ for $\mathrm{NH}_{4}-\mathrm{N}$.

\section{RESULTS AND DISCUSSION}

\section{ISE performance evaluation in laboratory}

The response times for increasing concentration changes were evaluated to about $2 \mathrm{~min}$ for the two sensors. The response times for decreasing concentration changes were found to be close to $15 \mathrm{~s}$ (Table 1). These results are consistent with response times given by the manufacturer $(<3 \mathrm{~min})$. The estimated response times seem to be sufficiently low to observe the variation of $\mathrm{NO}_{3}-\mathrm{N}$ and $\mathrm{NH}_{4}-$ $\mathrm{N}$ concentrations along the CWtw. Moreover, this result confirms that an acquisition frequency of $5 \mathrm{~min}$ is well adapted. 
Table 1 Results of the performance evaluation for the ISE probe obtained in laboratory. LoQs were analyzed with maximum permissible deviation (MPD) values of $30 \%$ and $60 \%$.

\begin{tabular}{llcc}
\hline & & $\mathbf{N O}_{\mathbf{3}} \mathbf{- N}$ sensor & $\mathbf{N H}_{\mathbf{4}} \mathbf{- N}$ sensor \\
\hline Response time (s) & to increasing concentrations & 130 & 125 \\
& to decreasing concenrations & 14 & 13 \\
\multirow{2}{*}{ LoQ (mgN/L) } & with 30\% MPD value & 0.5 & 1.0 \\
& with 60\% MPD value & 1.0 & 2.0 \\
Interference ratio & Chloride & negligeable & - \\
& Potassium & - & $1: 25$ \\
\hline
\end{tabular}

For each sensor, two LoQs have been verified depending on the maximum permissible deviation values (high value: 60\%; intermediate value: 30\%; Table 1) which are chosen by the laboratory based on its own expertise. Given that $\mathrm{NO}_{3}-\mathrm{N}$ and $\mathrm{NH}_{4}-\mathrm{N}$ concentrations measured along the CWtw are generally low and inferior to $2 \mathrm{mgN} / \mathrm{L}$, the lowest LoQs is chosen, i.e. $0.5 \mathrm{mgN} / \mathrm{L}$ for $\mathrm{NO}_{3}-\mathrm{N}$ and $1.0 \mathrm{mgN} / \mathrm{L}$ for $\mathrm{NH}_{4}-\mathrm{N}$, to allow the quantification of a maximum of data. In return, we assume a lower quality of data close to the LoQ concentrations.

According to manufacturer, chloride and potassium may be considered as the main interfering ions for $\mathrm{NO}_{3}-\mathrm{N}$ and $\mathrm{NH}_{4}-\mathrm{N}$ measurement, respectively. During the interference tests, the $\mathrm{NO}_{3}-\mathrm{N}$ concentrations remain rather constant with increasing chloride concentrations (Table 1). This suggests that the chloride interferences on $\mathrm{NO}_{3}-\mathrm{N}$ measurement may be considered as negligible despite chloride concentration variations observed along the CWtw (160-230 mg/L; data not shown). The $\mathrm{NH}_{4}-\mathrm{N}$ concentrations linearly increase with increasing potassium concentrations. The interference is evaluated to be $1 \mathrm{mgN} / \mathrm{L} \mathrm{NH}_{4}-\mathrm{N}$ for a potassium concentration increase of $25 \mathrm{mg} / \mathrm{L}$ (Table 1). The potassium concentrations measured along the CWtw varied from 15 to $25 \mathrm{mg} / \mathrm{L}$ (data not shown). This suggests that $\mathrm{NH}_{4}-\mathrm{N}$ concentrations are potentially interfered by $+/-0.2 \mathrm{mgN} / \mathrm{L}$ in the case of the studied CWtw and may be neglected. For both sensors, the estimated interferences are lower than those announced by the manufacturer ( $3 \%$ for chloride and $10 \%$ for potassium) and are consistent with the cross-sentivities values given by Winkler et al. (2004) with 1:300 for chloride and between 1:15 and 1:30 for potassium.

The verification of the linearity in the range of $0.5-100 \mathrm{mgN} / \mathrm{L}$ was performed by comparing, for each concentration, the mean bias $(n=6)$ with maximum permissible deviation values defined by the laboratory (Table 2). For $\mathrm{NO}_{3}-\mathrm{N}$ concentrations superior to $2.5 \mathrm{mgN} / \mathrm{L}$ and $\mathrm{NH}_{4}-\mathrm{N}$ concentrations superior to $5 \mathrm{mgN} / \mathrm{L}$, the mean bias were inferior to $20 \%$. For lowest concentrations the mean biases increased and ranged between $25 \%$ and $65 \%$ (Table 2). Increase of bias for low concentrations is consistent with electrochemical theory that suggests non-Nernstian response (i.e. nonlinear response) for low concentrations around few $\mathrm{mgN} / \mathrm{L}$ (e.g. Winkler et al. 2004). However, taking into 
account maximum permissible deviation values of $60 \%$ for concentrations lower than $5 \times$ LoQ concentrations and of $20 \%$ for higher concentrations, these results suggest that the linearity of the sensors may be verified from 0.5 to $100 \mathrm{mg} / \mathrm{L}$ for $\mathrm{NO}_{3}-\mathrm{N}$ and from 1 to $100 \mathrm{mg} / \mathrm{L}$ for $\mathrm{NH}_{4}-\mathrm{N}$. The estimated bias may be also used to compare concentrations measured by two different probes.

The repeatability, calculated as the standard deviation of the measurements of each concentration level, was generally better than $10 \%$ for both sensors and for the whole concentration range (Table 2). This low value may be used to evaluate significance of $\mathrm{NO}_{3}-\mathrm{N}$ and $\mathrm{NH}_{4}-\mathrm{N}$ concentration variations measured by a given probe.

Table 2 Mean relative bias $(n=6)$ and repeatability (calculated as standard deviation, $n=6$ ) for each tested concentration. The maximum permissible deviation (MPD) values were defined by the laboratory at $60 \%$ for concentrations inferior to $5 \times$ LoQ and at $20 \%$ for higher concentrations.

\begin{tabular}{|c|c|c|c|c|}
\hline \multirow{3}{*}{ Concentration (mgN/L) } & \multicolumn{2}{|c|}{$\mathrm{NO}_{3}-\mathrm{N}$ sensor } & \multicolumn{2}{|c|}{$\mathrm{NH}_{4}-\mathrm{N}$ sensor } \\
\hline & LoQ - 5×LoQ & $>5 \times \operatorname{LoQ}$ & LoQ - 5×LoQ & $>5 \times \operatorname{LoQ}$ \\
\hline & $0.5-2.5$ & $2.5-100$ & $1.0-5.0$ & $5.0-100$ \\
\hline Relative mean bias & $25 \%-46 \%$ & $-2 \%-20 \%$ & $32-64 \%$ & $-3-20 \%$ \\
\hline MPD values & $60 \%$ & $20 \%$ & $60 \%$ & $20 \%$ \\
\hline Repeatability & $7 \%-12 \%$ & $2 \%-7 \%$ & $4 \%-7 \%$ & $3 \%$ \\
\hline
\end{tabular}

\section{Cleaning frequency}

No strong difference (generally $<20 \%$ ) is observed between $\mathrm{NO}_{3}-\mathrm{N}$ and $\mathrm{NH}_{4}-\mathrm{N}$ concentrations measured before and after cleaning procedure (Figure 2), excepted for one probe for which stronger deviations are observed for the $\mathrm{NO}_{3}-\mathrm{N}$ sensor. Moreover, no difference has been observed between summer (maximum potential of biofouling development) and winter. Therefore, these results suggest that the biofouling impact may be considered as negligible for an exposure time of two weeks without any maintenance in this CWtw.
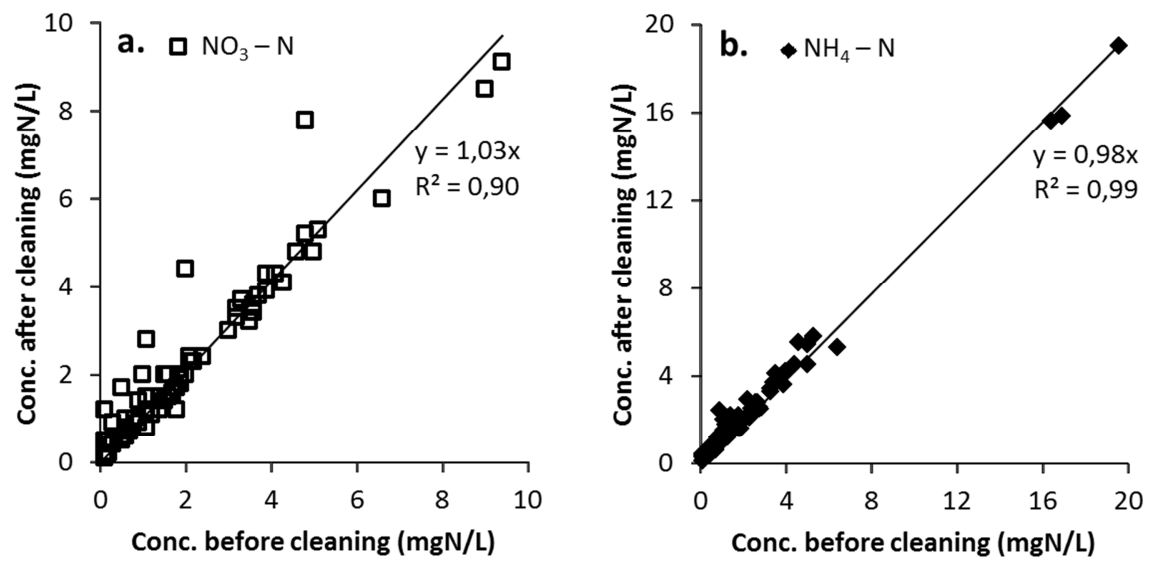

Figure $2 \mathrm{NO}_{3}-\mathrm{N}$ (a) and $\mathrm{NH}_{4}-\mathrm{N}$ (b) concentrations measured just before and after cleaning procedure by the 6 probes installed on the CWtw. 


\section{Evolution of the drift over time and correction}

This part is focused on the probe \#1 installed at the entry of the CWtw. The drift control procedure started 5 months after the installation of the probe and covered the 4 last months of the sensor life. The $\mathrm{NO}_{3}-\mathrm{N}$ concentrations measured in the drift control solutions stayed rather constant during the 4 last months (Figure 3a). Therefore, no correction is considered for the $\mathrm{NO}_{3}-\mathrm{N}$ signal.

Concerning $\mathrm{NH}_{4}-\mathrm{N}$ sensor, a drift is observed after 30 days of monitoring (Figure 3a). Assuming a linear drift over time, we estimate that $\mathrm{NH}_{4}-\mathrm{N}$ concentrations increased by $0.1 \mathrm{mgN} / \mathrm{L}$ every day. However, an offset daily correction of $0.1 \mathrm{mgN} / \mathrm{L}$ applied on the raw signal leads to negative values which suggests that the drift experimentally determined is overestimated. Another way to estimate the drift is possible thanks to the grab samples with concentrations below $0.10 \mathrm{mgN} / \mathrm{L}$ assuming that their corresponding probe concentrations should remain steady over time and form a baseline. Despite the low number of grab samples concentrations $(n=4)$, this baseline seems to increase linearly with time (Figure $3 \mathrm{~b}$ ). The slope of the relationship, i.e. $0.03 \mathrm{mgN} / \mathrm{L} / \mathrm{d}$, was used to estimate a more appropriate drift. The raw $\mathrm{NH}_{4}-\mathrm{N}$ signal was corrected by subtracting $0.03 \mathrm{mgN} / \mathrm{L} /$ day from November 2015.
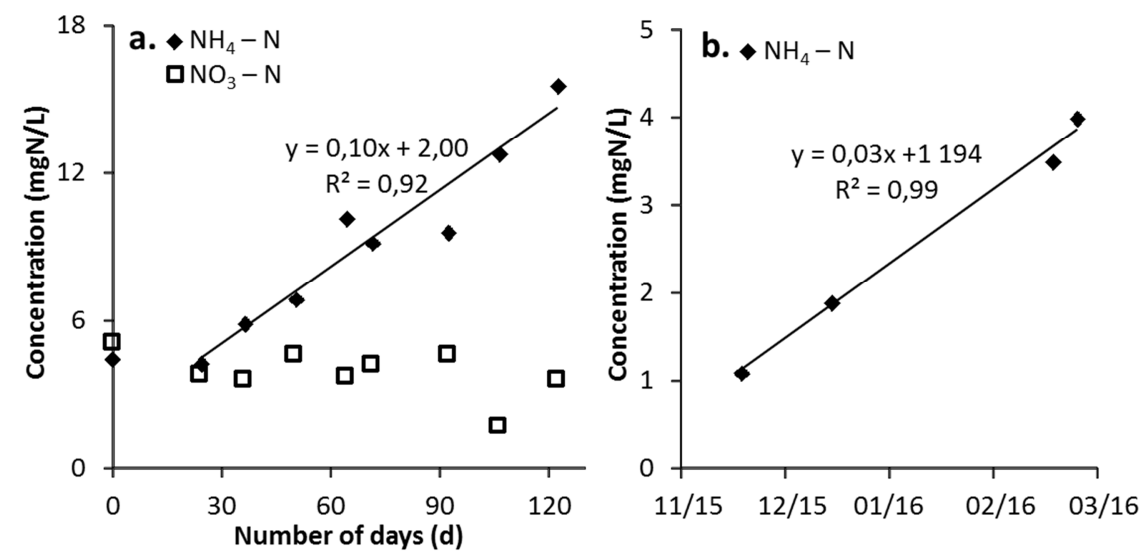

Figure 3 a) Evolution of the $\mathrm{NO}_{3}-\mathrm{N}$ (open squares) and $\mathrm{NH}_{4}-\mathrm{N}$ (black diamonds) concentrations measured by the probe (1) in the Sol $\mathrm{DC}_{\mathrm{C}}$ during the 4 last month of the sensor life. b) Evaluation of the $\mathrm{NH}_{4}-\mathrm{N}$ drift based on the increase in time of the $\mathrm{NH}_{4}-\mathrm{N}$ concentrations measured by the probe for the period where concentrations measured in the grab samples were low $(<0.10 \mathrm{mgN} / \mathrm{L})$.

\section{Local calibration and data validation}

After the drift correction, local calibration is completed using i) $50 \%$ of available couples of probe-grab sample points and ii) the 3 additional couples of adjusted concentration points (Figure 4a, 4b). Each slope of linear regression is used to correct the data measured by the probe. For the studied probe \#1, a correction by a factor 1.24 is applied on $\mathrm{NO}_{3}-\mathrm{N}$ concentrations (Figure 4a). The local calibration of $\mathrm{NH}_{4}-\mathrm{N}$ concentrations is more complex as all $\mathrm{NH}_{4}-\mathrm{N}$ concentrations measured into 
grab samples are always below $1 \mathrm{mgN} / \mathrm{L}$ (i.e. below the LoQ determined for the $\mathrm{NH}_{4}-\mathrm{N}$ sensor). In consequence, only the 3 additional couples of adjusted concentration (5, 10 and $15 \mathrm{mgN} / \mathrm{L})$ points are used to build the calibration curve (Figure $4 b$ ). For the probe \#1, a correction factor of 0.60 is applied to the $\mathrm{NH}_{4}-\mathrm{N}$ signal already corrected from the drift.
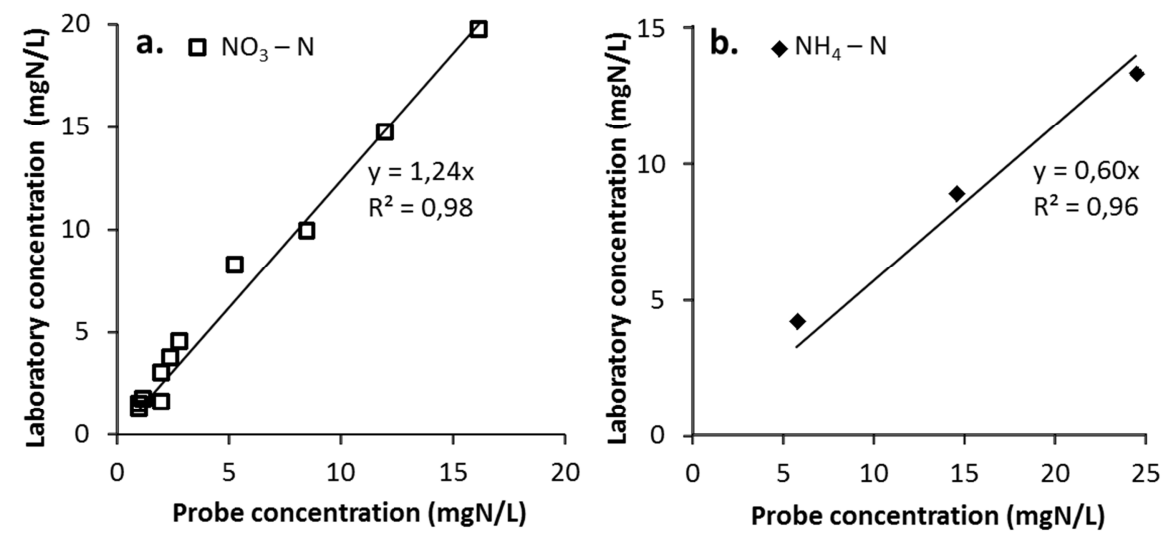

240 Figure $4 \mathrm{NO}_{3}-\mathrm{N}(\mathrm{a})$ and $\mathrm{NH}_{4}-\mathrm{N}$ (b) local calibrations performed for the probe \#1.

The other part of available couples of probe-grab sample points is used for data validation. Relative errors are calculated as the difference of the concentrations measured by the probe and measured in the grab sample and divided by the concentration measured in the grab sample. For $\mathrm{NO}_{3}-\mathrm{N}$ concentrations between LoQ and $5 \times$ LoQ (i.e. $0.5-2.5 \mathrm{mgN} / \mathrm{L}$ ), the relative errors are negative and close to $-30 \%$ (Table 3). For $\mathrm{NO}_{3}-\mathrm{N}$ concentrations superior to $5 \times$ LoQ (i.e. $2.5 \mathrm{mg} / \mathrm{L}$ ), the relative errors slightly decrease and varied between $-2 \%$ to $20 \%$ (Table 3 ). These results suggest that measurement by the ISE probe is of good quality for $\mathrm{NO}_{3}-\mathrm{N}$ monitoring in the CWtw. For $\mathrm{NH}_{4}-\mathrm{N}$, data for validation is not available as the whole dataset have been used for the local calibration. To remedy this situation, additional samples could be prepared using CWtw water spiked with $\mathrm{NH}_{4}-\mathrm{N}$ to cover the concentration range measured by the probe (until $40 \mathrm{mgN} / \mathrm{L}$ ). Half of these samples could be used for local calibration and the other half could be used for validation. Moreover, for the next dataset produced by new sensors, cross-validation will be considered to improve the local calibration and validation procedure. 
Table 3 Sample set used for validation of $\mathrm{NO}_{3}-\mathrm{N}$ measurement: raw probe concentrations, corrected probe concentrations (from local calibration) and reference laboratory concentrations. Relative errors between corrected and reference concentrations.

\begin{tabular}{ccccc}
\hline & $\begin{array}{c}\text { Raw conc. } \\
\text { (mgN/L) }\end{array}$ & $\begin{array}{c}\text { Corrected conc. } \\
(\mathbf{m g N} / \mathbf{L})\end{array}$ & $\begin{array}{c}\text { Reference conc. } \\
(\mathbf{m g N} / \mathbf{L})\end{array}$ & Relative error \\
\hline \multirow{2}{*}{$\mathbf{5} \times$ LoQ } & 0.8 & 1.0 & 1.4 & $-27 \%$ \\
& 1.2 & 1.5 & 2.0 & $-26 \%$ \\
\hline \multirow{3}{*}{$5 \times$ LoQ } & 3.3 & 4.1 & 4.1 & $-1 \%$ \\
& 3.8 & 4.7 & 3.9 & $20 \%$ \\
& 4.8 & 6.0 & 5.1 & $16 \%$ \\
& 5.2 & 6.5 & 6.6 & $-2 \%$ \\
\hline
\end{tabular}

\section{Example of data processing}

Figure 5 shows the raw $\mathrm{NO}_{3}-\mathrm{N}$ and $\mathrm{NH}_{4}-\mathrm{N}$ concentrations measured by the probe (\#1) and the corrected concentrations. Drift correction has only been performed for $\mathrm{NH}_{4}-\mathrm{N}$ signal, while local calibration correction has been applied for $\mathrm{NO}_{3}-\mathrm{N}$ and $\mathrm{NH}_{4}-\mathrm{N}$ signals. During the 9-month studied period, the $\mathrm{NO}_{3}-\mathrm{N}$ concentrations monitored at the entry of the CWtw are clearly variable and ranged between the LoQ value $(0.5 \mathrm{mgN} / \mathrm{L})$ and $\sim 13 \mathrm{mgN} / \mathrm{L}$ (Figure $5 \mathrm{a})$. Only few values are below the LoQ ( $<10 \%$ of data). Daily variations are observed with maximum concentrations generally measured around midnight (Figure 5a). The amplitude of theses variations are far greater than the measurement repeatability evaluated in the laboratory $(<10 \%)$, confirming the significance of the $\mathrm{NO}_{3}-\mathrm{N}$ daily peaks. Only in situ and continuous measurement allows the observation of $\mathrm{NO}_{3}-\mathrm{N}$ concentration dynamic at this temporal scale over long period.

Contrary to $\mathrm{NO}_{3}-\mathrm{N}$, data treatment has strongly modified the $\mathrm{NH}_{4}-\mathrm{N}$ concentrations (Figure $5 b$ ) and corrected $\mathrm{NH}_{4}-\mathrm{N}$ concentrations are $~ 2$-fold lower than the raw concentrations. Several $\mathrm{NH}_{4}-\mathrm{N}$ peaks are observed with maximum $\mathrm{NH}_{4}-\mathrm{N}$ concentrations reaching $15 \mathrm{mgN} / \mathrm{L}$. These peaks are not easily observable with traditional monitoring (i.e. weekly sampling and analysis in laboratory). Unfortunately, the validation of $\mathrm{NH}_{4}-\mathrm{N}$ data is less effective than for $\mathrm{NO}_{3}-\mathrm{N}$ due to very low concentrations in the grab samples. About $50 \%$ of data are below the LoQ (i.e. $1 \mathrm{mgN} / \mathrm{L}$ ).

The performance evaluation of sensors in laboratory coupled with the quality procedure on the field help to improve the quality of data exploitation. The knowledge of the probe limitations (e.g. LoQ, response time, repeatability...) avoids misinterpretations of temporal $\mathrm{NO}_{3}-\mathrm{N}$ and $\mathrm{NH}_{4}-\mathrm{N}$ recordings. For example, we recommend to not discuss concentrations inferior to $0.5 \mathrm{mgN} / \mathrm{L}$ for $\mathrm{NO}_{3}-$ $\mathrm{N}$, inferior to $1 \mathrm{mgN} / \mathrm{L}$ for $\mathrm{NH}_{4}-\mathrm{N}$. In case of nitrogen flux estimation along the CWtw, the values inferior to the LoQ may be replaced by LoQ/2 values. Furthermore, an apparent $\mathrm{NH}_{4}-\mathrm{N}$ increase can be the result of the signal drift and not the degradation of water quality entering into the CWtw (for example the global increase observed since November 2015 on the raw signal, Figure 5b). Differences of $\mathrm{NO}_{3}-\mathrm{N}$ and $\mathrm{NH}_{4}-\mathrm{N}$ concentrations measured by a probe at different times or by several 
probes in different locations may be now discussed in regards of the evaluated bias, relative errors and repeatability.
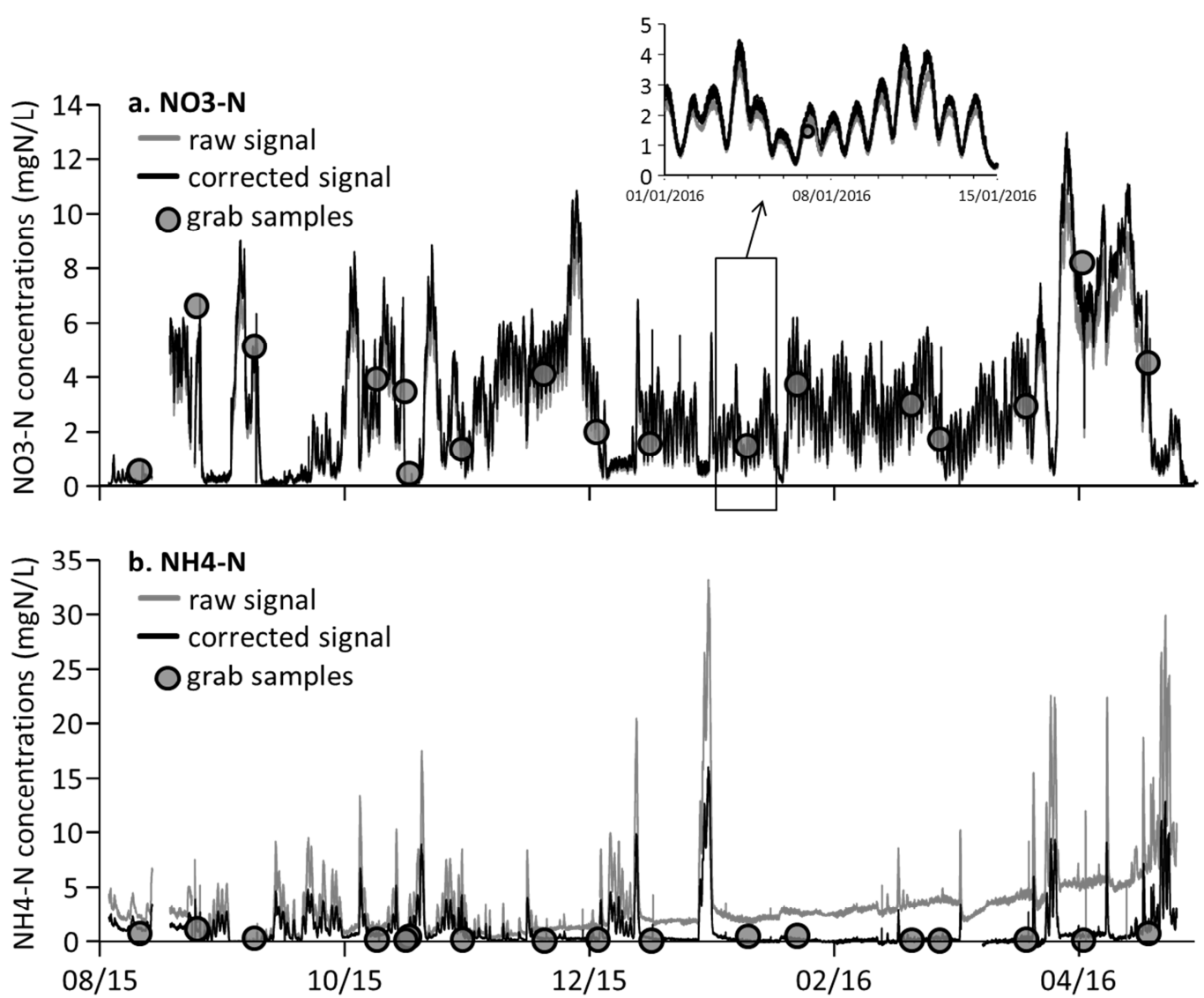

Figure 5 Raw signals (black lines) recorded by the probes \#1 for $\mathrm{NO}_{3}-\mathrm{N}$ (a) and $\mathrm{NH}_{4}-\mathrm{N}$ (b) during August 2015 to March 2016 and signals after correction procedures. The black circles represent the grab samples and the dashed lines represent the LoQ estimated for the probe.

\section{CONCLUSIONS}

The methodology implemented for the monitoring of low $\mathrm{NO}_{3}-\mathrm{N}$ and $\mathrm{NH}_{4}-\mathrm{N}$ concentrations in a CWtw has allowed an efficiency correction of produced data. This methodology is firstly based on an evaluation in the laboratory of the sensor performances (mainly LoQs and repeatability of the measurements). Specific procedures have been implemented to correct data. The evaluation of the potential impact of the biofouling shows that a 2-week maintenance frequency is sufficient. The monitoring of signal drift show no drift for the $\mathrm{NO}_{3}-\mathrm{N}$ signal whereas $\mathrm{NH}_{4}-\mathrm{N}$ signal drift can been corrected using grab samples. Despite initial calibration and matrix adjustment, a local calibration with grab samples is necessary. Observing these procedures for data correction, a good agreement exists between corrected probe concentrations and reference concentrations measured in the laboratory. The consolidated data made it possible a reliable quantification of $\mathrm{NO}_{3}-\mathrm{N}$ and $\mathrm{NH}_{4}-\mathrm{N}$ concentrations along the CWtw and a better interpretation of the temporal recordings of low 
concentrations, taking into account the technical limitations of the probes (mainly LoQ and repeatability). The presented methodology still needs to be improved by i) the production of $\mathrm{NH}_{4}-\mathrm{N}$ concentrated samples for validation, ii) the use of cross validation, or iii) data comparison of two probes installed at the same location.

\section{Acknowledgments}

The authors thank the AFB (the French National Agency for Biodiversity) for providing financial support to this work (ZRV program http://zrv.irstea.fr). We gratefully acknowledge the following Irstea colleagues for field campaigns and chemical analysis: Myriam Arhror, Jérémie Aubert, Vincent Bourgeois, Corinne Brosse, Clément Crétollier, Olivier Garcia and Loïc Richard.

\section{References}

Åmand L., Olsson G., Carlsson B. 2013. Aeration control - a review. Water Science and Technology, 67(11), 2374-2398.

Cammann K. 1979 Working with Ion-Selective Electrodes. Springer-Verlag, Heidelberg.

Guigues N., Roy S. \& Vaute L. 2002 Mesure en continu in situ des concentrations en nitrates et chlorures dans les eaux naturelles à l'aide d'une sonde multiparamètre (Continuous in situ measurement of nitrate and chloride in natural waters with a multi-parameter probe). BRGM Report, BRGM/RP-51276-FR, France.

Kaelin D., Rieger L., Eugster J., Rottermann K., Bänninger C. \& Siegrist H. 2008 Potential of in-situ sensors with ion-selective electrodes for aeration control at wastewater treatment plants. Water Science and Technology, 58(3), 629-637.

NF EN ISO 10304-1 Water quality - Determination of dissolved anions by liquid chromatography of ions - Part 1: Determination of bromide, chloride, fluoride, nitrate, nitrite, phosphate and sulfate 2009, AFNOR, La Plaine Saint-Denis, France.

NF EN ISO 14911 Water quality - Determination of dissolved $\mathrm{Li}^{+}, \mathrm{Na}^{+}, \mathrm{NH}^{+}, \mathrm{K}^{+}, \mathrm{Mn}^{2+}, \mathrm{Ca}^{2+}, \mathrm{Mg}^{2+}, \mathrm{Sr}^{2+}$ and $\mathrm{Ba}^{2+}$ using ion chromatography 1999, AFNOR, La Plaine Saint-Denis, France.

NF EN ISO 15839 Water quality - On-line sensors/analysing equipment for water - Specifications and performance tests 2003, AFNOR, La Plaine Saint-Denis, France.

NF T 90-210 Water quality - Protocol for the initial method performance assessment in a laboratory 2009, AFNOR, La Plaine Saint-Denis, France.

Olsson, G., Carlsson B., Comas J., Copp J., Gernaey K.V., Ingildsen P., Jeppsson U., Kim C., Rieger L., Rodriguez-Roda I., Steyer J.-P., Takacs I., Vanrolleghem P.A., Vargas A., Yuan Z. \& Amand L. 2014 Instrumentation, control and automation in wastewater - from London 1973 to Narbonne 2013. Water Science and Technology, 69(7), 1373-1385. 
Prost-Boucle S. \& Boutin C. 2013 Etat des lieux national des Zones de Rejet Végétalisées (ZRV) (National Overview of Constructed Wetlands receiving treated wastewater). ONEMA-Irstea Report, France.

345 Rieger L., Siegrist H., Winkler S., Saracevic E., Votava R. \& Nadler J. 2002 In-situ measurement of ammonium and nitrate in the activated sludge process. Water Science and Technology, 45(4-5), 93-100.

Thomann M., Rieger L., Frommhold S., Siegrist H. \& Gujer W. 2002 An efficient monitoring concept with control charts for on-line sensors. Water Science and Technology, 46(4-5), 107-116.

350 Winkler S., Rieger L., Saracevic E., Pressl A. \& Gruber G. 2004 Application of ion-sensitive sensors in water quality monitoring. Water Science and Technology, 50(11), 105-114. 